\title{
NÍVEL TECNOLÓGICO E BALANÇO ECONÔMICO DE PRODUÇÃO DE MAMONA PARA OBTENÇÃO DO BIODIESEL NO ESTADO DO CEARÁ ${ }^{1}$
}

\author{
Ahmad Saeed Khan ${ }^{2}$ \\ Francisco Laercio Pereira Braga \\ Ruben Dario Mayorga
}

\begin{abstract}
Resumo - Dada a necessidade de conhecer melhor a viabilidade econômica e o nível tecnológico de produção da mamona (Ricinus communis) no Estado do Ceará, considerado um dos maiores produtores de oleaginosas no Nordeste do Brasil, este trabalho objetivou determinar o nível tecnológico e elaborar um balanço econômico da produção de mamona para obtenção de biodiesel no Estado do Ceará. A pesquisa foi realizada nos municípios de Boa Viagem, Tauá e Pedra Branca. Foram utilizados dados primários recolhidos dos produtores, em entrevistas diretas. $\mathrm{Na}$ identificação do nível tecnológico foram consideradas as técnicas recomendadas para o cultivo da mamona. $\mathrm{Na}$ análise da rentabilidade foram considerados as receitas e os custos de produção por hectare, nos municípios selecionados. Os principais resultados obtidos na pesquisa indicam que, em média, $12,91 \%$ dos agricultores entrevistados empregam mais de $80 \%$ da técnica recomendada para o cultivo da mamona. A produção de mamona cearense, nos três municípios analisados, mostrou-se rentável, tendo sido a utilização de mão-de-obra familiar um fator primordial para se ter baixo custo de produção.
\end{abstract}

Palavras-chave: mamona, nível tecnológico, biodiesel, balanço econômico, Ceará.

Recebido em: 14/02/08 Aceito em: 30/04/08

2 Eng-Agrônomo, Ph. D. em Economia Agrícola e Recursos Naturais. Professor Titular do Departamento de Economia Agrícola da Universidade Federal do Ceará, Bolsista CNPq. Email: saeed@ufc.br

3 Economista, Mestre em Economia Rural da Universidade Federal do Ceará.

E-mail: laercio.braga@bol.com.br

4 Economista. Ph.D. Professor Associado do Departamento de Economia Agrícola,Universidade Federal do Ceará.Email: dario@ufc.br 


\section{Introdução}

\subsection{O problema e sua importância}

O biodiesel está surgindo, nos últimos anos, como opção de combustível alternativo, comumente obtido a partir de óleos vegetais (dendê, babaçu, coco, caroço de algodão, pinhão manso, girassol, soja e mamona) e animais modificados quimicamente. Vários países já estão produzindo o biodiesel em escala industrial, sendo a União Européia um dos maiores produtores e consumidores desse tipo de óleo no mundo. Dentre os países, podemse citar Alemanha, França, Itália e Suécia; na Alemanha há a maior concentração de usinas, e os Estados Unidos são outro importante país produtor de biodiesel à base de soja (Paulillo et al., 2007).

No Brasil, a agricultura de energia vem ampliando sua produção em decorrência da modernização da agricultura; o que resulta na elevação da produtividade sem comprometimento da área destinada à agricultura de alimento. Este é o diferencial que distingue o Brasil dos demais produtores de biodiesel (Paulillo et al., 2007).

As principais matérias-primas para produção nacional do biodiesel são algodão, amendoim, babaçu, canola, dendê, girassol, macaúba, mamona, entre outros.

A mamona é uma cultura difundida em praticamente todo o território brasileiro, tendo já ocupado posição de destaque no agronegócio do país, com potencial para soerguer e contribuir para o desenvolvimento agrícola sustentável. Encontra-se bastante expandida nos estados do Nordeste, onde existem cerca de 3 milhões de hectares aptos ao cultivo da mamona. Com exceção de Sergipe e Maranhão, todos os estados do Nordeste têm tradição na exploração de mamona, sendo a Bahia o maior produtor, seguida pelo Ceará (Alves; Sobrinho; Carvalho, 2004). A mamona destaca-se, ainda, como uma cultura de grande apelo social, pois pode ser cultivada com outras culturas, como feijão, amendoim, milho, entre outras. 
No Estado do Ceará, especificamente no final de 2005 (dois anos após a implantação do $\mathrm{PNPB}^{5}$ ), começou oficialmente a produção de mamona, destinada, primordialmente, à indústria brasileira de biodiesel - o que reforça a idéia da importância desse assunto para a economia cearense. Inicialmente, o projeto no semi-árido cearense funcionou em caráter experimental. Para desenvolver o referido projeto, o governo do estado, juntamente com a prefeitura municipal e o consórcio de empresas termoelétricas, contou com o apoio da Empresa Brasileira de Pesquisa Agropecuária (EMBRAPA) e da Fundação Núcleo de Tecnologia Industrial (NUTEC).

A produção de mamona, para utilização na produção de biodiesel como novo combustível, depende, entre outros fatores, de uma relação positiva entre a energia consumida no processo e a energia disponibilizada pelo combustível produzido.

Outro ponto importante refere-se à avaliação econômica do processo de produção da mamona. Essa avaliação poderá fornecer informações relevantes para possíveis tomadas de decisões de custos, pois permitirá correta manutenção e operação de máquinas e implementos, caso esteja havendo uso inadequado que gere ineficiência produtiva.

Por fim, um aspecto relevante que chamou a atenção para o desenvolvimento deste trabalho encontra-se no fato de não existirem dados conclusivos sobre a viabilidade econômica da mamona para obtenção de biodiesel no Nordeste e, especificamente, no Estado do Ceará. Os objetivos deste artigo são: a) Mensurar o nível tecnológico dos produtores de mamona nos municípios de Boa Viagem, Tauá e Pedra Branca, no Estado do Ceará; b) Analisar a rentabilidade econômica da produção de mamona nos municípios selecionados.

O artigo está organizado em quatro seções, além desta introdução. A segunda trata de referencial teórico de inovação tecnológica e balanço

Programa Nacional de Produção e Uso de Biodiesel, que estabelece as condições legais para a introdução do biodiesel na Matriz Energética Brasileira de combustíveis líquidos. A forma de implantação do PNPB fo estabelecida por meio do Decreto, de 23 de dezembro de 2003 (MINISTÉRIO DE MINAS E ENERGIA, 2006). 
econômico; a terceira aborda os aspectos metodológicos, como fonte de dados, tamanho de amostra e, em seguida, métodos de análise. Na quarta seção são apresentados os resultados, por meio de tabelas e discussão destas. Finalmente, a quinta seção encerra o artigo, com resumo das principais conclusões e sugestões.

\section{Referencial teórico}

\subsection{Inovações tecnológicas}

Dentro da linha de pensamento econômico, é consenso a idéia de que a tecnologia desempenha importante papel para o desenvolvimento econômico, sendo as inovações tecnológicas pilares importantes para alcançar esse desenvolvimento e, conseqüentemente, aumentar a produtividade dos fatores de produção.

As definições do termo tecnologia são numerosas, e algumas delas são bastante restritivas. De acordo com uma delas, a tecnologia é essencialmente conhecimento, ou seja, conhecimento útil, visto que pode ser aplicada às atividades humanas e contribuir para elevação quantitativa e qualitativa dos resultados de tais atividades e processos. Pode-se colocar a inovação tecnológica como a aplicação de uma nova tecnologia ao processo produtivo, que resulta em novo produto, ou altera algum atributo do produto antigo pelo mercado, ocasionando níveis mais elevados de produtividade e de lucratividade, além de aumentar a participação no mercado da empresa inovadora (Rosenthal, 1995).

A inovação tecnológica engloba alguma mudança no conjunto dos conhecimentos tecnológicos utilizados pela empresa, como, por exemplo, a adoção de uma nova forma de organização, a criação de uma nova tecnologia ou de um novo produto ou, também, o aperfeiçoamento dos métodos de fabricação, que causaria melhor acabamento, qualidade ou confiabilidade do bem. Com isso, a inovação torna-se o principal determinante do aumento da produtividade e da geração de oportunidade 
de investimento. Uma característica central da inovação tecnológica nas economias industrializadas é a crescente incorporação do conhecimento científico aos processos mais simples de geração de riqueza.

Muitas teorias vêm, ao longo dos anos, procurando explicar a importância da tecnologia para o crescimento econômico. Para os economistas clássicos, a teoria econômica já colocava as inovações tecnológicas como condicionante fundamental para o desenvolvimento econômico (Freitas, 2003).

No livro A riqueza das Nações, de Adam Smith (1983, apud Matos, 2005), as mudanças tecnológicas associadas ao processo de divisão do trabalho são fatores que determinam o aumento da produtividade. No setor agrícola, embora pudesse se beneficiar desse processo, seus efeitos são de menor intensidade do que nos setores manufaturados.

Adam Smith destacou os fatores e ingredientes essenciais do que veio a ser chamada inovação tecnológica e colocou a constante incorporação de conhecimento aos processos e produtos - o que a torna ingrediente essencial para a competitividade da empresa (Cruz; Perez, 2001).

David Ricardo tinha uma visão, "a priori”, mais cética das possibilidades de crescimento da economia, principalmente no que se refere aos impactos significativos e sustentáveis do progresso técnico sobre os ganhos de produtividade agrícola. No entanto, posteriormente, ele observou que uma das formas de evitar a estagnação da economia seriam os ganhos de produtividade do trabalho e da terra, via progresso tecnológico (Silva, 1995, apud Matos, 2005).

Para Smith e Ricardo, a concorrência é inseparável do desenvolvimento econômico e um método de distribuir os frutos do progresso técnico. Para Ricardo, o progresso técnico (que consistia, essencialmente, na introdução de novas máquinas) traduzia-se na diminuição dos custos de produção, que, conseqüentemente, por ação da concorrência, se traduziriam inteiramente em diminuição dos preços (Sylos Labini, 1984). 
De acordo com Braga (2006), Marx enfatizou o papel da inovação na elevação da taxa de lucro e na concorrência intercapitalista, propiciando, a um só tempo, a economia de capital, a elevação da taxa de mais-valia e uma posição privilegiada de uma empresa em relação às demais. Para Karl Marx, a capacidade de mudanças estruturais via inovações é endógena à economia capitalista e resulta da concorrência, que se torna um mecanismo permanente de introdução de progresso técnico (Possas, 2002, apud Matos, 2005), ou seja, a adoção das inovações é incentivada pela competição entre os capitalistas e é responsável pela dinâmica do processo de acumulação (Sousa, 2000).

Na Teoria do Desenvolvimento Econômico, Schumpeter defendeu a tecnologia como elemento essencial da dinâmica capitalista, considerando, ainda, as inovações como fatores endógenos ao sistema econômico capitalista, devido à busca de novas oportunidades lucrativas por parte das empresas em sua interação competitiva. Para o autor, a inovação tecnológica é um fenômeno puramente econômico da história do capitalismo; assim, elaborou a teoria da inovação. A inovação, nesse contexto, tem sentido amplo; não engloba apenas alterações tecnológicas, mas também toda e qualquer mudança no espaço econômico promovida pela empresa em busca de vantagens para obtenção de ganhos competitivos, além da introdução e da exploração de novos produtos, processos, insumos e formas de organização (Matos, 2005).

Segundo Freitas (2003), a Teoria Neoclássica não se aprofundou nos assuntos relacionados com tecnologia até meados da década de 50 (séc. $\mathrm{XX}$ ), quando os autores, em seus modelos de crescimento econômico, enfatizavam terra, capital e trabalho e, apesar de reconhecerem o progresso tecnológico, não o incluíam formalmente no modelo.

Hicks, neoclássico, durante os anos de 1930, introduziu o conceito de inovação induzida, cuja escassez dos fatores de produção constitui o elemento indutor, na medida em que o produtor busca tecnologias que economizem o fator produtivo mais escasso e, conseqüentemente, mais caro. 
Nos anos de 1950 surgem modelos de economia dual, em que a adoção de inovações tecnológicas no setor agrícola é vista como condição necessária ao desenvolvimento econômico (Silva, 1995 apud Braga, 2007). A dualidade tecnológica, nesse panorama, consiste no fato de existirem, numa mesma região, produtores que empregam modernas técnicas de produção, enquanto outros têm reduzido nível tecnológico.

Os níveis de produtividade de uma empresa podem elevar-se com a adoção de novas tecnologias, agrícolas ou não, e beneficiar, positivamente, a economia. Embora as tecnologias sejam de conhecimento de todos os produtores, nem todos as adotam por vários fatores, entre eles, os socioeconômicos (Khan et al., 1991, apud Matos, 2005).

A agricultura no mundo, especialmente no Brasil, vem passando por mudanças expressivas nos últimos vinte anos, prenunciando a constituição de um padrão produtivo e tecnológico extremamente dinâmico. A agricultura está cada vez mais diversificada, visto que passou a incorporar inovações de produto e de processos, integrou-se aos demais setores da economia e tornou-se o centro das atenções no comércio internacional na formação de políticas ambientais (Gonçalves da Silva; Melo, 2001).

Os mercados de produtos agrícolas e agroindustriais estão mais competitivos com o passar dos anos, e as tecnologias são elementos centrais na busca de competitividade. Logo, commodities, mercados, produtos e insumos diferenciados têm demanda qualificada de conhecimento de base científica e tecnológica (Gonçalves da Silva; Melo, 2001)

A atividade agrícola, diante de toda a revolução tecnocientífica ocorrida em vários setores da economia, foi afetada pela incorporação de inovações mecânicas, químicas e genéticas na sua base produtiva (Freitas, 2003).

Contudo, alguns desafios requerem implementação de políticas tecnológicas voltadas para as atividades ligadas ao agronegócio. São eles: a) Produzir mais, degradando menos, e a custos competitivos; b) 
Gerar capacidade de diferenciação de produtos e de mercados; c) Abrir espaço para produtores marginalizados e dar condições de expansão àqueles já inseridos no agronegócio (Gonçalves da Silva; Melo, 2001).

A busca por ganhos de produtividade no setor agrícola é um estímulo importante para o surgimento de novas bases de conhecimento, acentuando o papel do desenvolvimento científico e tecnológico para a produção agropecuária e agroindustrial.

Uma das consequiências das revoluções tecnológicas no setor rural foram aumento da produção e da produtividade, fornecimento de mão-de-obra para as indústrias, desenvolvimento do comércio internacional, declínio da população rural e maior atenção à pesquisa em vários ramos.

\subsection{Balanço econômico}

Um dos principais gargalos que ocorrem em estudos sobre técnicas operacionais de produção agropecuária está relacionado com a carência de avaliação econômica. $\mathrm{O}$ custo de produção é a soma de valores de todos os recursos (insumos) e serviços utilizados no processo produtivo de certa atividade.

A análise dos custos incide, ainda, na determinação de todas as despesas envolvidas na produção de determinado produto, em certo período, acrescido de seus custos de oportunidade e depreciações. Portanto, o estudo de custo de produção é de suma importância para o empresário rural, governo e instituições, tendo em vista o melhor planejamento da unidade produtiva, orientando, assim, a escolha das atividades e a combinação dos recursos utilizados na produção (Silva Filho, 2004).

Segundo Hoffmann et al. (1987), existem diversos significados de custos de produção. Um refere-se ao ponto de vista do homem de negócios, em que os custos a serem considerados irão depender da finalidade em vista da decisão que se quer tomar. Logo, quando se apura o lucro, incluem-se 
nesses custos as despesas diretas, as depreciações, o juro, o aluguel e os impostos.

Assim, as determinações de custos servem, de modo geral, para conseguir vários objetivos. Para o agricultor, por exemplo, serve como elemento auxiliar de sua administração na escolha das culturas, criações e práticas a serem utilizadas, e os resultados serão também fonte de dados para o governo e entidades de classe, pois fornecerão subsídios à formulação de sua política agrícola.

A análise da viabilidade econômica da empresa rural fornece a base para a identificação do nível de eficiência em que a empresa opera. Logo, quando se tem posse dos indicadores econômicos, o administrador pode planejar suas decisões com possibilidades de alterá-las ou não, dependendo do resultado. Por esse motivo, torna-se necessário que o administrador conheça as variáveis ou fatores que influenciam, tanto direta quanto indiretamente, os resultados dos negócios (Silva Filho, 2004).

Existem inúmeros indicadores de avaliação econômica que visam, principalmente, comparar os resultados obtidos em sistemas de produção agropecuários. Contudo, cada técnica de avaliação possui tanto limitações quanto vantagens. Dependendo de qual seja o objetivo a ser alcançado, há índices que se prestam melhor para determinada finalidade, pois permitem que se consiga analisar os resultados mais facilmente (Maya, 2003).

\section{Material e métodos}

\subsection{Origem dos Dados}

Os dados utilizados foram de origem primária, obtidos de entrevistas diretas junto aos produtores de mamona, nos meses de novembro e dezembro de 2006, nos municípios de Tauá, Boa Viagem e Pedra Branca, maiores produtores de mamona no Estado do Ceará. 


\subsection{Amostra}

A amostra selecionada corresponde a $50 \%$ do total de produtores de mamona cadastrados em cada município. Dessa forma, o total de entrevistados, em três municípios, foi de 62 produtores, sendo 21 em Boa Viagem, 11 em Tauá e 30 em Pedra Branca.

\subsection{Métodos de análise}

\subsubsection{Mensuração do nível tecnológico}

No cálculo do nível tecnológico foram consideradas as técnicas indicadas como as mais adequadas à atividade de plantação da mamona; no cálculo dos índices tecnológicos foram utilizados pesos.

O índice tecnológico do produtor $j\left(\mathrm{I}_{j}\right)$ foi calculado pela seguinte expressão:

$$
I_{j}=\frac{1}{m} \sum_{i=1}^{m} \frac{a_{i j}}{w_{i}},
$$

em que i é i-ésima técnica $(\mathrm{i}=1, \ldots, \mathrm{m}) ; \mathrm{m}$, número de técnicas; $\mathrm{j}, \mathrm{j}$-ésimo produtor de mamona $(\mathrm{j}=1, \ldots, \mathrm{z}), \mathrm{a}_{\mathrm{ij}}$, valor obtido da técnica i pelo produtor $\mathrm{j} ; \mathrm{e}_{\mathrm{i}}$, valor máximo da técnica i.

Como índice tecnológico médio dos produtores de mamona (IT) considerou-se o do somatório dos $I_{j}$ dividido pelo número de produtores, conforme abaixo:

$$
I T=\frac{1}{z} \sum_{j=1}^{z} I_{j}
$$


em que $\mathrm{j}$ é j-ésimo produtor de mamona $(\mathrm{j}=1, \ldots, \mathrm{z})$ e $\mathrm{z}$, número de produtores de mamona.

\subsubsection{Operacionalização das variáveis}

No cálculo dos índices tecnológicos foram atribuídos pesos conforme a Tabela 1.

Tabela 1 - Técnicas indicadas para o cultivo de mamona e seus respectivos pesos

Técnica

Espaçamento

Profundidade

Sementes

Período do Plantio

Período da Capina

Período da Colheita
Espaçamento recomendado Espaçamento não recomendado

Profundidade recomendada Profundidade não recomendada

Sementes distribuídas pelo Governo

Sementes distribuídas por Empresas Sementes selecionadas pelo próprio produtor

Não selecionadas

Período recomendado

Período não recomendado

Período recomendado

Período não recomendado

Período recomendado Período não recomendado
2

Valor

2

1

2

1

4

3

2

1

2

1

1

2

1

Fonte: CEARÁ (2006). 
Os níveis tecnológicos dos produtores de mamona foram determinados com base nos índices já citados, que variam de um (1) a zero (0). Quanto mais próximo de um (1), melhor o nível tecnológico.

Para tornar possível uma comparação dos níveis tecnológicos entre os produtores, foram definidos os seguintes padrões, com base nos intervalos de variação dos valores dos índices:

- Padrão A: $\quad$, Padrão B: $0,5<I_{j} \leq 0,8$, Padrão C: $0 \leq I j \leq 0,5$, em que $\mathrm{I}_{\mathrm{j}}$ é o valor de um índice tecnológico do produtor $\mathrm{j}$.

\subsubsection{Análise econômica}

Existem inúmeros indicadores de avaliação econômica que visam, principalmente, comparar os resultados obtidos em sistemas de produção agropecuários.

Tais indicadores são de suma importância para o processo de tomada de decisão. Entretanto, para que se consiga determiná-los é necessário estabelecer critérios adequados de medição dos custos e das receitas que estão incluídas na atividade.

As medidas de rentabilidade utilizadas neste estudo basearam-se nos indicadores usados por Martin et al. (1998, apud Carvalho, 2000). 


\section{Resultados da discussão}

\subsection{Nível tecnológico}

Nesta seção encontra-se a análise do nível tecnológico com base nos padrões definidos na metodologia para o índice tecnológico de determinado produtor de mamona $\left(I_{j}\right)$ e índice tecnológico médio dos produtores $\left(I T_{n}\right)$.

Em 2006, com relação à tecnologia recomendada pelos técnicos ao cultivo da mamona nos municípios estudados, $87,09 \%$ dos produtores de mamona da amostra total foram classificados no padrão B e $12,91 \%$, no padrão A. Assim, 87,09\% dos produtores empregaram entre 50\%, exclusive, e $80 \%$ da tecnologia recomendada pelos técnicos e 12,91\% utilizaram mais de $80 \%$ da tecnologia recomendada. O percentual de produtores que pertencia ao padrão B era elevado, devido ao fato de muitos produtores não receberem assistência técnica adequada e, quando a recebiam, não seguirem as orientações recomendadas, por questões culturais e econômicas (Figura 1).

Deve ser mencionado que um dos fatores que contribuíram para que $12,91 \%$ dos produtores estivessem no padrão A está relacionado com as épocas adequadas de plantio, capina e colheita, conforme orientação dos técnicos. 


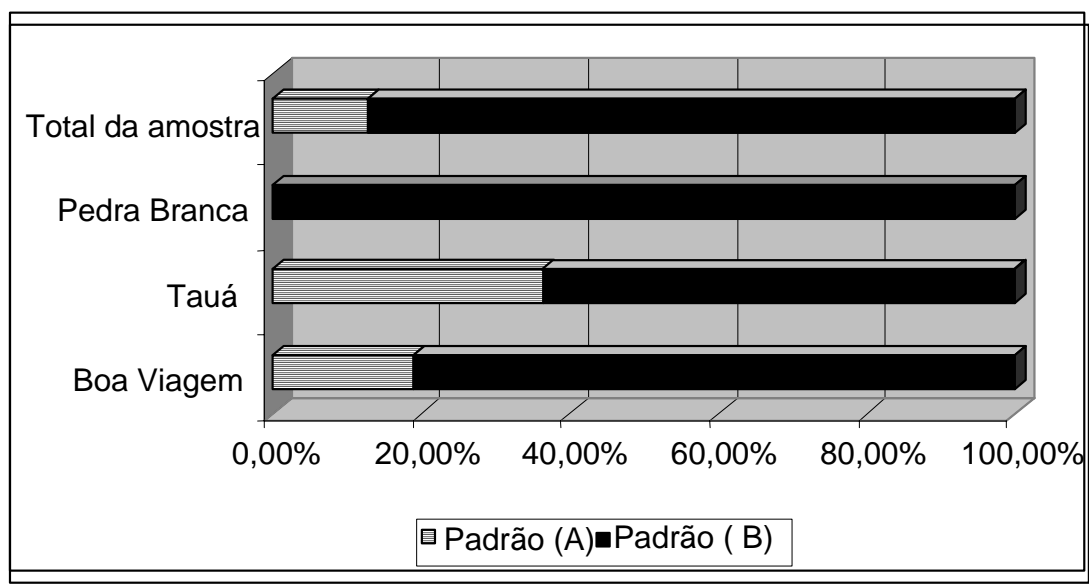

Figura 1 - Frequiência relativa dos produtores de mamona em relação ao índice tecnológico (I) - municípios selecionados, Ceará/ 2006.

Fonte: Resultado da pesquisa.

Entre os municípios pesquisados, Tauá foi o que apresentou melhor resultado de índice tecnológico, conforme $36,36 \%$ dos entrevistados no padrão A, seguido do município de Boa Viagem, com 19,05\% no padrão A e $80,95 \%$, no B. Esse resultado pode ser atribuído à qualidade da assistência técnica recebida pelos pesquisados e à qualidade das sementes utilizadas na plantação. O que teve menor desempenho foi Pedra Branca, com $100 \%$ no padrão B. Em nenhum dos municípios visitados havia produtores no padrão $\mathrm{C}$, ou seja, nenhum deles utilizava $50 \%$ ou menos da tecnologia recomendada.

O menor índice tecnológico da amostra total foi de 0,58 e pertencia a alguns produtores dos municípios de Boa Viagem e Pedra Branca, os quais utilizaram $58 \%$ da tecnologia recomendada. Tauá destaca-se entre os municípios da pesquisa, por ter pelo menos três produtores de mamona que obtiveram o maior valor do índice tecnológico $(0,91)$, o que significa que os produtores utilizavam $91 \%$ das tecnologias recomendadas. $\mathrm{O}$ município que registrou menor desvio-padrão foi Pedra Branca, o que 
sugere que, no ano em estudo, houve maior uniformização da tecnologia recomendada utilizada pelos produtores deste município (Tabela 2).

Tabela 2 - Valores médios, mínimo, máximo e desvio-padrão do índice tecnológico do produtor em relação à tecnologia do cultivo da mamona (municípios selecionados/2006)

Fonte: Resultade da pesquisa. Valor Valor Desvio

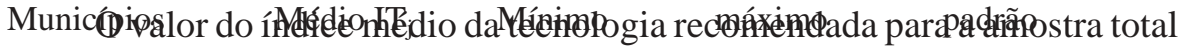
ficou em torno de 0,73, o que indica que, em média, os produtores

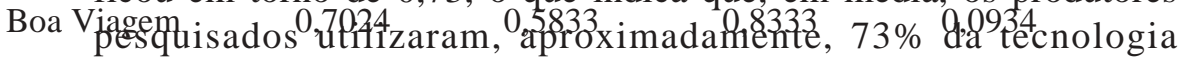
Tauá recomendada do cultivg, da mamong,909s produtores de Tauá apresentaram, em média, o maior îndice tecnologico. Vale fazer referência

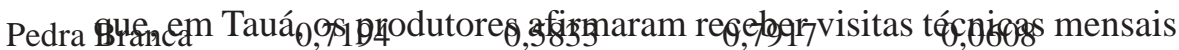
dos técnicos da EMATERCE local, ao contrário dos outros municípios, e

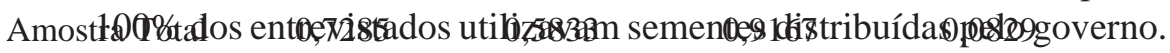

O baixo nível tecnológico dos produtores de Pedra Branca pode ser justificado pelo fato de apenas $40 \%$ dos produtores utilizarem sementes próprias e os outros $60 \%$ receberem sementes doadas pela empresa Brasilecodiesel, cuja produtividade da cultura é menor do que as sementes distribuídas pelo governo do estado. 


\subsection{Análise da rentabilidade financeira da produção de mamona}

Antes da apresentação dos resultados da análise da rentabilidade, faz-se necessário fazer algumas observações sobre os dados analisados. Primeiramente, a maioria dos produtores utilizou o método consorciado para plantação, o que causou uma análise diferenciada em relação aos custos direcionados ao cultivo desta. Então, para os cálculos de custos relacionados com depreciação, capital empatado, mão-de-obra contratada e manutenção, os gastos foram rateados pelo método da participação da cultura da mamona no valor da produção total da propriedade, pois a mamona é, na maioria das propriedades, cultivada com outras culturas como feijão e milho. Então, muitos dos instrumentos agrícolas que os agricultores usavam eram utilizados, conjuntamente, nas culturas.

Conforme Tabela 3, dos municípios selecionados, Tauá foi o que obteve a maior receita bruta média por hectare. Esse fato pode ser decorrente de dois fatores: primeiro, maiores preços recebidos com a venda do produto; segundo, produtividade mais elevada no município devido à presença do cultivo da mamona isoladamente ou consorciada com feijão. A menor receita bruta média por hectare obtida foi no município de Pedra Branca, decorrente de produtividade baixa, com usos inadequados de técnicas de cultivo e baixa qualidade da semente de mamona usada pelo agricultor.

Os maiores custos por hectares foram dos produtores de Tauá e os menores, dos produtores de Pedra Branca. De forma geral, considerando a amostra total, os dados da Tabela 3 indicam que a atividade mostrou-se rentável, quando se observa o custo total da produção por hectare médio, sem considerar o custo da mão-de-obra familiar. Em 2006, em média, esse custo representou 34,2\% do valor da receita bruta. Em Pedra Branca, o custo total da produção por hectare (CTP/ha) teve a maior representatividade, $51,2 \%$. O menor percentual desse custo na receita bruta foi de 30,5\%, no caso do município de Tauá. 
Quando se considera o custo total de produção por hectare médio, incluindo mão-de-obra familiar, a sua participação na receita bruta por hectare médio elevou-se consideravelmente. Contudo, Tauá manteve-se com o menor percentual (52,5\% da receita), enquanto em Pedra Branca os custos ultrapassaram a receita bruta por hectare e a mamona apresentou-se como não-rentável no município, nessas condições.

Tabela 3 - Receita bruta e custos de produção por hectare nos municípios selecionados, Ceará (valores médios em R\$, novembro/2006 )

\begin{tabular}{l|c|c|ccc}
\hline Município & $\begin{array}{c}\text { Receita } \\
\text { Bruta } \\
\text { (RB/ha) }\end{array}$ & $\begin{array}{c}\text { Custo } \\
\text { Operacional } \\
\text { Efetivo } \\
\text { (COE/ha) }\end{array}$ & $\begin{array}{c}\text { Custo } \\
\text { Operacional } \\
\text { Total } \\
\text { (COT/ha) }\end{array}$ & $\begin{array}{c}\text { Custo Total da } \\
\text { Produção } \\
\text { (CTP/ha) }\end{array}$ & $\begin{array}{c}\text { Custo Total de } \\
\text { Produção } \\
\text { (CTP/ha)* }\end{array}$ \\
\hline Boa Viagem & 179,76 & 36,56 & 40,52 & 56,31 & 132,83 \\
Tauá & 356,89 & 90,99 & 100,68 & 109,05 & 187,52 \\
Pedra Branca & 49,23 & 17,40 & 18,93 & 25,23 & 70,57 \\
Amostra & 148,03 & 36,94 & 40,75 & 50,62 & 112,40 \\
Total
\end{tabular}

Fonte: Resultado da pesquisa.

Nota: CTP*-Custos total incluindo mão-de-obra familiar.

$\mathrm{Na}$ determinação do Custo Operacional Efetivo (COE)/ha, que corresponde às despesas efetivamente desembolsadas, levaram-se em consideração os insumos (sementes, defensivos e gastos com sacos) e a mão-de-obra contratada (diaristas, considerando uma jornada de $8 \mathrm{~h} / \mathrm{dia}$ ) utilizada na produção da mamona, por produtor.

O maior COE/ha médio foi observado no município de Tauá, correspondendo ao valor de $\mathrm{R} \$ 90,99$, sendo que o maior peso na formação do $\mathrm{COE}$ ficou por conta dos gastos com insumos, principalmente sementes, que correspondem a $62 \%$ deste. Na amostra total, o valor correspondente a este custo foi de $\mathrm{R} \$ 36,95$, tendo os insumos contribuídos com $75,8 \%$ destes. 
O valor do COE/ha do município de Tauá representou 25,5\% da Receita Bruta (RB) por hectare médio. Já na amostra total, o COE/ha correspondeu a $24,95 \%$ da RB por hectare. Tais valores demonstram que a produção da mamona, cujo objetivo nos três municípios é extração do biodiesel, é uma atividade relativamente de baixo desembolso, pois, depois de pagos os custos efetivamente desembolsados pelo produtor, ainda sobra uma parcela de recursos para estes.

Deve-se mencionar que o baixo desembolso realizado com gastos com diaristas na produção decorre de do fato de que, por exemplo, na fase de colheita e debulha geralmente é utilizada a mão-de-obra familiar, que não exige o pagamento efetivo de diárias; as diaristas contratadas pelos agricultores, como foi dito em todas as entrevistas, fazem o trabalho de limpeza do terreno, que normalmente é cultivado em consórcio com outras culturas. Por esse motivo, a participação da mão-de-obra temporária teve percentual bem pequeno na formação do custo efetivo da produção de mamona, nos municípios selecionados.

No cálculo do Custo Operacional Total por hectare médio (COT/ha), agregaram-se ao valor do COE as despesas com depreciação, manutenção, seguro, encargos financeiros e outras despesas operacionais. No caso da depreciação e manutenção, foi utilizado novamente o método de rateio de custos por participação na produção, pois normalmente os equipamentos (enxadas, facão e foice) utilizados pelos produtores servem também para o cultivo de outras culturas. Por esse motivo, as despesas relativas destes eram pequenas nos municípios selecionados, já que os produtores não possuíam equipamentos específicos ao manejo da cultura.

O maior valor médio correspondente ao COT/ha foi do município de Tauá, $\mathrm{R} \$ 100,68$, e o maior peso na sua composição foi do item $\mathrm{COE} / \mathrm{ha}$ (insumos e mão-de-obra), assim como também ocorreu nos outros municípios.

O valor do COT/ha na produção de mamona, no município de Boa Viagem, foi, em média, de $22,5 \%$ da RB/ha média gerada da produção. Já nos 
municípios de Tauá e Pedra Branca, essa proporção foi maior; correspondeu a $28,2 \%$ e a $38,4 \%$ da RB/ha, respectivamente. Na amostra total, o COT/ha médio equivaleu a $27,5 \%$ da RB/ha. Dessa forma, percebe-se que a receita bruta cobriu novamente, com certa tranqüilidade, os custos de produção.

No cálculo do Custo Total da Produção por hectare (CTP/ha) incluemse o valor do COT/ha e a remuneração do capital e da terra. Inicialmente, calculou-se o CTP/ha sem utilização da mão-de-obra familiar e, posteriormente, foi incluída esta despesa no indicador.

Os municípios de Tauá e Boa Viagem foram os que tiveram maiores $\mathrm{CTP} /$ ha médios, $\mathrm{R} \$ 109,05$ e $\mathrm{R} \$ 56,31$, respectivamente, valores superiores ao da amostra total, que foi de $\mathrm{R} \$ 50,62$. Em todos os municípios constatou-se que o valor da participação do CTP/ha médio na RB/ha média chegou, no máximo, a 51\%, caso do município de Pedra Branca. $\mathrm{Na}$ amostra total, os CTP/ha médios corresponderam a 34,2\% do total das RB/ha média. Esses resultados reforçam, claramente, que as receitas brutas cobrem os custos totais de produção médios por hectare.

Contudo, ao analisar o CTP/ha, incluindo os possíveis gastos que ocorreriam com o pagamento da mão-de-obra familiar, amplamente utilizada nas fases de colheita e beneficiamento da mamona, os resultados se alteraram expressivamente. Os valores foram altos em todos os municípios entrevistados, mas somente no município de Tauá o valor desse custo chegou a ser $52,2 \%$ do valor da receita bruta por hectare, enquanto em Boa Viagem essa proporção elevou-se para 73,8\% da RB/ ha média. No caso de Pedra Branca, merece ser destacado que, se fossem considerados os gastos com mão-de-obra familiar nos custos da produção, a cultura da mamona não seria rentável, pois as receitas não cobririam o valor dos custos por hectare. Assim, conseqüentemente, o maior peso no valor dos CTP/ha médios seriam os gastos com mão-deobra familiar. 
O comportamento dos produtores de Tauá é o mais interessante dos três municípios pesquisados, pois quantidade maior de produtores obteve um resultado mais expressivo em termos de valores reais no que se refere ao lucro bruto por hectare, apresentando receitas brutas bem acima de seus custos de produção por hectare. O maior lucro bruto por hectare do produtor deste município foi de $\mathrm{R} \$ 526,34$ e o de menor lucro, de $\mathrm{R} \$$ 28,62 . Esse comportamento pode ser explicado pelo fato de Tauá ter apresentado o melhor resultado em termos de padrão tecnológico, ou seja, os produtores utilizaram a tecnologia recomendada pelos técnicos, o que proporcionou maior produtividade à cultura, além de serem mais mobilizados que os dos outros municípios, pois participavam das reuniões da associação à qual pertenciam.

Pedra Branca foi o município que registrou o menor lucro bruto, entre os produtores pesquisados. O maior lucro foi de $\mathrm{R} \$ 93,66$. Nesse município observou-se, ainda, o maior número de agricultores com lucratividade negativa (cerca de seis produtores), ou seja, seus custos foram superiores às receitas no ano de 2006, resultado este decorrente do fato de esses produtores não usarem as tecnologias recomendadas pelos técnicos que prestavam assistência a eles.

\subsubsection{Determinação dos Indicadores de Rentabilidade para produção por hectare}

Ao analisar os indicadores da Tabela 4, é possível verificar o desempenho financeiro da atividade nos municípios entrevistados. Considerando a amostra total, o fluxo de caixa por hectare médio (dado pela diferença entre a receita bruta por hectare médio e o custo operacional total por hectare médio, não incluindo a depreciação) foi, em média, igual a $\mathrm{R} \$$ 108,16, sendo que os municípios de Tauá e Boa Viagem foram os que obtiveram os maiores fluxos de caixa.

Os resultados das Margens Brutas e Pontos de Nivelamento são encontrados na Tabela 4. Os produtores de mamona de Boa Viagem, em 
média, apresentaram o maior valor da margem bruta, em relação ao custo operacional efetivo por hectare $\left(\mathbf{M B}_{\mathbf{C O E}}\right)$, que é de 391,65\%, seguido por Tauá, 292,23\%, o que indica que, após os produtores de mamona, em conjunto e em cada município, pagarem os custos operacionais efetivos, eles dispunham ainda de 391,65\% e 292,23\% sobre o valor desse custo, respectivamente. Na amostra total, a $\mathbf{M B}_{\mathbf{C O E}}$ foi de $300,68 \%$, ou seja, após os produtores pagarem seus custos efetivos, ainda tinham recursos financeiros para cobrir os demais, o que equivalia ao triplo, em média, do valor do COE.

No que se refere às margens brutas em relação aos custos operacionais totais e custos totais de produção, percebe-se que Boa Viagem teve a maior margem bruta em relação ao custo operacional total por hectare $\left(\boldsymbol{M B}_{\text {сот }}\right)$, cerca de 343,63\%, o que significa que, ao serem pagos os custos operacionais totais, a disponibilidade de recursos para pagar os demais custos fixos, o risco e a capacidade empresarial, em média, corresponde a, aproximadamente, mais que o triplo do valor do COT/ha. $\mathrm{Na}$ amostra total, o valor dessa margem por hectare foi de $263,25 \%$, valor considerado expressivo para uma análise de rentabilidade da produção de mamona.

A terceira margem a ser analisada é relacionada com custo total por hectare médio $\left(\boldsymbol{M B} \boldsymbol{B}_{\boldsymbol{C T P}}\right)$, que se obtém após efetuar os pagamentos de todos os custos, incluindo a remuneração do capital e da terra. Para esse indicador, Tauá foi o município que apresentou o maior valor da $\boldsymbol{M B}_{\text {CTP }}$ (cerca de 227,26\%). 
Tabela 4 - Indicadores de rentabilidade da produção de mamona por hectare - municípios selecionados, Ceará/2006

Fonte: Resultado da pesquisa.

Quanto aos pontos de nivelamento, na mostra total foram necessários $62,62 \mathrm{~kg}, 69,06 \mathrm{~kg}$ e $85,80 \mathrm{~kg}$ de mamona para cobrir o custo operacional efetivo por hectare, o custo operacional total por hectare e o custo total de produção por hectare, respectivamente.

O ponto de nivelamento em relação ao $\operatorname{COT}\left(\boldsymbol{P} N_{c o T}\right)$, no município de Tauá, foi de $167,81 \mathrm{~kg}$, ou seja, para cada hectare plantado foram necessários $167,81 \mathrm{~kg}$ de mamona para cobrir os custos operacionais totais. Com relação ao CTP, foram necessários $181,75 \mathrm{~kg}$ de mamona para cobrir os custos de produção total por hectare, nesse município.

O Lucro Operacional (LO) por hectare, que corresponde à diferença entre a receita bruta por hectare médio (RB/ha) e o custo Operacional Total por hectare médio (COT/há) foi o mais elevado no município de Indicadore

$$
\begin{aligned}
& \text { Fluxo de } \mathrm{C} \\
& \mathrm{MB}_{\mathrm{COE}(\%)} \\
& M B_{C O T(\%)} \\
& M B_{C T P(\%)} \\
& P N_{C O E(\%)} \\
& P N_{C O T}(\%) \\
& P N_{C T P}(\%) \\
& \mathrm{LO}(\mathrm{R} \$) \\
& \mathrm{IL}(\%)
\end{aligned}
$$

Tauá, correspondendo a R \$265,90, enquanto em Boa Viagem e Pedra Branca, o valor correspondente foi de $\mathrm{R} \$ 143,20$ e $\mathrm{R} \$ 31,84$, respectivamente. 
No caso da amostra, ao analisar o LO por hectare, obteve-se o valor de $\mathrm{R} \$ 111,08$, e o Índice de Lucratividade (IL) por hectare foi de 75,04\%. Tais valores reforçam que a produção de mamona é uma atividade rentável e que proporcionou alta lucratividade no ano em estudo. Boa Viagem e Tauá foram os municípios que tiveram maior IL por hectare, cerca de 79,6\% e 74,50\%, respectivamente, e Pedra Branca, apesar das dificuldades apresentadas, teve um IL, por hectare, de $64,67 \%$, valor considerado significativo.

\section{Conclusões e sugestões}

O nível tecnológico médio dos produtores de mamona, nos três municípios analisados, revela que $12,91 \%$ deles empregavam mais de $80 \%$ da tecnologia recomendada pelos técnicos e $87,09 \%$, entre $50 \%$ e $80 \%$ da tecnologia recomendada. Esse elevado percentual de produtores pertencentes ao padrão B pode ser explicado pela má qualidade de distribuição de semente e da assistência prestada nos municípios, principalmente em Pedra Branca e Boa Viagem, onde os agricultores não confiavam nas recomendações fornecidas pelos técnicos.

A produção da mamona mostrou-se rentável nos municípios selecionados. No município de Pedra Branca, os custos ultrapassaram a receita bruta por hectare, quando foi considerado o custo relativo à mão-de-obra familiar no custo total da produção por hectare.

Diante desse quadro, surgem algumas sugestões para melhorar a produtividade das regiões analisadas:

- Aumentar o preço mínimo oferecido pela mamona;

- Fazer um trabalho de adubagem do terreno, com ajuda dos técnicos que dão assistência local; 
- Oferecer uma assistência técnica de qualidade e com menor intervalo de tempo;

- Receber apoio maior das instituições públicas para o cultivo, por meio de empréstimos mais facilitados.

\section{Referências}

ALVES, M. O.; SOBRINHO, J. N.; CARVALHO, J. M. M. de. Possibilidade da mamona como fonte de matéria-prima para a produção de biodiesel no Nordeste brasileiro. Fortaleza: BNB, 2004. 41 p. (Documentos do ETENE. Nº1).

BRAGA, W. D. Teoria do desenvolvimento econômico: uma investigação sobre lucros, capital, crédito, juro e o ciclo econômico. Texto eletrônico. Revista de Ciência da Informação v. 7 n. $1 \mathrm{fev} / 2006$. Disponivel em: < http://www.dgz.org.br/fev06/ F_I_rec.htm>. Acesso em: 28 de Fev. 2007.

BRAGA, F.L.P. Balanço econômico da produção de mamona e energético de biodiesel no Estado do Ceará. 2007. 137f. (Dissertação de Mestrado em Economia Rural). Departamento de Economia Agrícola, Centro de Ciências Agrárias, Universidade Federal do Ceará. Fortaleza, 2007.

BRASIL. MINISTÉRIO DE MINAS E ENERGIA (MME). Biodiesel: o novo combustível do Brasil. Programa Nacional de Produção e uso do Biodiesel. 2004. Disponível em <http:// www.mme.gov.br/ > acesso: em 15 Ago. 2006.

CARVALHO, C. A. V. de. Análise econômica da revitalização do algodão no Estado do Ceará. 2000. 53f. (Dissertação de Mestrado em Economia Rural). Departamento de Economia Agrícola, Centro de Ciências Agrárias, Universidade Federal do Ceará. Fortaleza, 2000. 
CEARÁ. Empresa de Assistência Técnica e Extensão Rural do Ceará (EMATERCE).

Revitalização da cultura da mamona. Disponível em< http:// www.ematerce.ce.gov.br/>. Acesso em: 11 Dez. 2006.

CRUZ, C. H. de B; PEREZ, J. F. Inovação tecnológica e a FAPESP. Revista Pesquisa

FAPESP: Ciência e Tecnologia no Brasil. Edição Impressa 69, 2001. Disponível em

< ht t p :// w w w.revistapes quis a.fapes p.br/ index.php?art=1571\&bd=1\&pg=1\&lg>. Acesso em: 28 Fev. 2007.

FREITAS, D. G. F. Nível tecnológico e competitividade da produção de mel de abelhas (Apis mellifera) no Ceará. 2003. 101f. (Dissertação de Mestrado em Economia Rural). Departamento de Economia Agrícola, Centro de Ciências Agrárias, Universidade Federal do Ceará. Fortaleza, 2003.

GONÇALVES DA SILVA, C.; MELO, L. C. P. de (Cord). Ciência, tecnologia e inovação: desafio para sociedade brasileira. Livro Verde. Brasília. Ministério da Ciência., 2001. 250p.

HOFFMANN, R.; ENGLER, J.J.C.; SERRANO,O.; THAME, A.C.M.; NEVES, E.M. Administração de empresa agrícola. 5ed. São Paulo: Pioneira, 1987.325p.

MATOS, V. D. de. A apicultura no Estado do Ceará: competitividade, nível tecnológico e seus fatores condicionantes, produção e exportação de mel natural. 2005. 189f. (Dissertação de Mestrado em Economia Rural). Departamento de Economia Agrícola, Centro de Ciências Agrárias, Universidade Federal do Ceará. Fortaleza, 2005. 
MAYA, F. L. A. Produtividade e viabilidade econômica da recria e engorda de bovinos em pastagens adubadas intensivamente com e sem o uso da irrigação. Piracicaba. 2003. 83f. (Dissertação de Mestrado). Universidade de São Paulo (USP), 2003.

ROSENTHAL, D. Inovação tecnológico: uma solução de arcabouço conceitual de referencia. In: ROSENTHAL, D.; MEIRA, S.L. (org.). Os primeiros 15 anos da política nacional de informática: o paradigma e sua implementação. Recife: CNPq/PROTEM-CC, 1995. 285p.

PAULILLO, L.F.; VIAN, C.E. de F.; SHIKIDA, P.F.A.; MELLO, F.T. de. Álcool combustível e biodiesel no Brasil: quo vadis?. Revista de Economia e Sociologia Rural, Brasília, v.45, n.03. p.531-565, jul./set., 2007.

SILVA FILHO, C. B. da. Análise técnica e econômica da atividade leiteira em três propriedades da bacia leiteira de Parnaíba - Piauí. 2004. 86f. (Dissertação de Mestrado em Economia Rural). Departamento de Economia Agrícola, Centro de Ciências Agrárias, Universidade Federal do Ceará. Fortaleza, 2004.

SOUZA, F. L. Estudo Sobre O Nível Tecnológico da Agricultura Familiar no Ceará.

2000. 107f. (Dissertação de Mestrado em Economia Rural). Departamento de Economia Agrícola, Centro de Ciências Agrárias, Universidade Federal do Ceará. Fortaleza, 2000.

SYLOS LABINI, P. Oligopólio e progresso técnico. São Paulo: Abril Cultural, 1984. 199p. 
Abstract - In order to determine technological level and economic balance of castor seed prodution (Ricinus communis) in the State of Ceará, one of the main producers of oil seed of Northeast of Brazil, the present research was coducted to verify economic feasibility and technological level of castor seed production for obtaining biodiesel. The data were collected in Boa Viagem, Tauá and Pedra Branca municipalities. For profit analysis, income and production cost per hectare of castor seed production in selected municipalities were considered. It was observed that on the average, $12,91 \%$ of the interviewed farmers are using more than $80 \%$ of the recommended techniques. The castor seed production in all the three selected municipalities is economically feasifble (profitable), without considering the cost related to family labor.

Key words: castor seed, technological level, biodiesel, economic feasibility, Ceará. 
REVISTA DE ECONOMIA E AGRONEGÓCIO, VOL.6, $N^{\circ} 1$ 